\title{
THE INFORMATIONAL CONTENT OF THE BALANCE SHEET AND THE ACCOUNTING INTERNATIONAL ARMONIZATION
}

\author{
Assistant Ph.D. Student Gomoi Bogdan Cosmin,_bogdan_gomoi@yahoo.com \\ University „Aurel Vlaicu” of Arad
}

\begin{abstract}
The new economical vocabulary revolves around some very well defined concepts: globalization, modularization, informational society, etc. In this context each field of the economy suffers transformations and the rhythm of these transformations is also very alert. In the financialaccounting field, the new tendencies concern the comparability of the annual financial statements of the companies in order to send a very accurate information about the company, that can be "read" and interpreted from any point of the world and also for creating some pertinent comparative analysis. One of the purposes of these trials is to facilitate the financial analysis and to make the synthesis documents more eloquent for the users of the accounting information.
\end{abstract}

An accurate image and the comparability of the information, is the ultimate purpose desired by all the followers of the harmonization of accounting standards. This is a movement, which will receive - in time - a recognized spot in the history of accountancy and administration. Thus indirect, it is recognized the essential role of the financial analysis in the diagnosis of the economical and financial „health" of the company. For now, it is hard to appreciate if Romania is prepared for the harmonization from economical and social point of view. The present Romanian society, finds itself in a period of transition, trying to solve its problems through the adheration to the solutions proposed by international accounting standards, so the Minister of Public Finances elaborated the accounting reglementations of harmonization of the Romanian accounting system with the foresights of the forth directive of EEC and with those of the International Accounting standards, and lately with those of the Seventh Directive of the EEC also. In the first stage of Romanian accountancy standardization, the Romanian standardizers choose a model of balance sheet, inspired from the French accounting environment, which corresponds with the bilateral scheme rendered in the article 9 from the Directive. In the second stage of Romanian accountancy standardization, out of the wish to align to the International Accounting Standards, the standardizers choose a new model of balance sheet which was in concordance with the IAS 1, and coming closer to the way of shaping and presentation typical for the Anglo-Saxon accountancy models.

In the third stage, the new balance sheet format, is approved through OMPF no. 1752 from 2005 , oriented with prevalence towards the analysis „liquidity - solvability” being in concordance with the foresights of the Forth Directive of European Economic Community and with the modifications and later edits. In essence this was adopted for the harmonization of the Romanian accounting reglementations with the Forth Directive of the EEC and with the International Accounting Standards. This order must be interpreted and applied in correlation with the Law of Accountancy no. 82 from 1991 and with the International Financial Reporting Standards (IFRS). Present tendencies of the economical world are going towards the financial analysis, correlated with the preoccupations concerning the assets market and informational theories. Financial analysis offers this information to a whole set of users, eager to estimate correctly the financial health of those companies they are interested in. 
The balance sheet between the Forth Directive of the European Economic Community and the Romanian accounting regulations

The Forth European Directive is imposing mandatory schemes concerning the settle of the balance sheet, centering on the strictness of the shape in the presentation of the accounting information. The Directive is offering two possibilities of presenting the accounting balance sheet (bilateral and list), but the Romanian „standardizers" expressed their option for the scheme described in the article 10 of the Directive (format list), respecting in all the structures and the judgments of this one.

My purpose in the next paragraph is a small comparative analysis, between the balance sheet (format list), foreseen by the Directive in article 10, and the balance sheet foreseen by OMPF no. 1725 from 30.11.2005.

\begin{tabular}{|c|c|}
\hline $\begin{array}{l}\text { The simplified balance sheet (format list), } \\
\text { foreseen by the Forth Directive in art. } 10 . \\
\text { Format I }\end{array}$ & $\begin{array}{l}\text { The simplified balance sheet foreseen by } \\
\text { OMPF no. } 1725 \text { from } 30.11 .2005 \\
\text { Format II }\end{array}$ \\
\hline $\begin{array}{l}\text { A. Unpaid - in capital } \\
\text { B. Constitute costs (the way they are defined in } \\
\text { the national legislation, and the way they } \\
\text { authorize the into active) } \\
\text { C. Long term assets } \\
\text { I. Intangible assets } \\
\text { II. Plant assets } \\
\text { III. Financial assets } \\
\text { D. Current assets } \\
\text { I. Inventories } \\
\text { II. Receivable accounts } \\
\text { III. Marketable securities } \\
\text { IV. Amounts in bank accounts, in postal checks, } \\
\text { checks and cash } \\
\text { E. Deferred revenues } \\
\text { F. Current liabilities: notes payable in one year } \\
\text { G. Current assets } \\
\text { H. Total assets minus current liabilities } \\
\text { I. Long- Term liabilities: notes payable in more } \\
\text { than one year } \\
\text { J. Provisions for risk and other costs } \\
\text { K. Regularization accounts } \\
\text { L. Owned assets } \\
\text { I. Paid in capital } \\
\text { II. Accumulated other comprehensive income } \\
\text { III. Reserves from reevaluation } \\
\text { IV. Reserves } \\
\text { V. Retained loss or earnings }\end{array}$ & $\begin{array}{l}\text { A. Long term assets } \\
\text { I. Intangible assets } \\
\text { II. Plant assets } \\
\text { III. Financial assets } \\
\text { B. Current assets } \\
\text { I. Inventories } \\
\text { II. Receivable accounts } \\
\text { III. Short term investments } \\
\text { IV. Cash and bank accounts } \\
\text { C. Prepaid expenses } \\
\text { D. Current liabilities: notes payable in one or } \\
\text { less then year } \\
\text { E. Net current assets/net current liabilities } \\
\text { F. Total assets minus current liabilities } \\
\text { G. Long-Term liabilities: notes payable in more } \\
\text { than one year } \\
\text { H. Provisions } \\
\text { I. Prepaid incomes } \\
\text { J. Capital and reserves } \\
\text { I. Subscribed capital } \\
\text { II. Primes of capital } \\
\text { III. Reserves out of reevaluation } \\
\text { IV. Reserves } \\
\text { V. Retained loss or earnings } \\
\text { VI. Current loss or earnings }\end{array}$ \\
\hline
\end{tabular}

Exhibit 1: Comparative analysis of the balance sheet

Even though the new balance sheet respects almost all the judgments seized in the format list - foreseen in the article 10 from the Directive - there are some small differences. The Directive foreseen the registration of the subscribed and unpaid-in capital as a distinct heading before the constitute costs (line A format I), while as in the balance sheet approved by OMFP no. 1725 from 
2005, this heading appears in the structure of current assets (line B II, format II), and is entitled „Receivable accounts” concerning the „subscribed and unpaid-in capital”. The Forth Directive gives the possibility to the national legislation to stipulate the registration of the subscribed and unpaid-in capital as a component element of the current assets. „Constitute costs” is still maintained as a distinct heading in the structure of long term assets (line AI from format II), although this aspect creates an incompatibility with the stipulations of the standard IAS 1, but not with the stipulations of the Directive. In the balance sheet format described by the article 10 of the Directive, the „constitute costs" are kept as a distinct heading before the long term assets (line B, format I). The Forth Directive gives the possibility to the national legislation to stipulate the registration of „Constitute costs” as a component element of the active.

In the Directive the c appear cumulated with the development costs, with the explanation, that research costs will be capitalized only when the national legislation allows this thing. In the new balance sheet foreseen by OMPF no. 1725 from 30.11.2005, the ,research costs" were „extracted" from the structure of plant assets. The Romanian standardizes respected the stipulations of the international accounting standard IAS 38 ,Intangible Assets”, according to which, ,research costs" must be seen as costs, only when they were preformed. According to the Directive, the „,conversion differences”, and also the ,primes concerning the repayment of the securities" are highlighted as distinct headings in the balance sheet. In the new balance sheet foreseen by OMPF no. 1725 from 30.11.2005, „conversion differences” were eliminated from the balance sheet, being „towed" to the black box, while the ,primes concerning the repayment of the securities" represent fictitious active, were extracted from the loans based on market securities, and constituted as a distinct heading.

Current liabilities are ordinarily presented in the order of maturity as follows (lines F and I from format I, and also lines D and G from format II), and current assets are presented in order of their capacity to primarily convert into cash (line DII from format I and line BII from format II). This presentation of liabilities and assets offers the possibility, of a very complex analysis of the companies' liquidity and solvability ratio. The way the headings are ordered and grouped in the balance sheet - format list, allows the possibly of getting some indicators, useful in the financial analysis of the company. (Working balance necessary: line $\mathrm{G}$ from format $\mathrm{I}$, or line $\mathrm{E}$ from format II and permanent assets: line H from format I, or line F from format II). The option of the Romanian standardizes for - the format list - which was not stipulated by OMF no. 94 from 2001 eases the analysis of the company's financial situation by the ratio liquidity - solvability.

\section{The balance sheet between IAS1 and Romanian accounting regulations}

The Romanian standardizes adopted a model of balance sheet which, although starts from the Forth European Directive, tries to fulfill the stipulations and requirements presented in the international standard IAS1.The accounting and conceptual environment of IASC doesn't impose a definite format for the balance sheet, but defines the active, the liability and owned capital, definitions accompanied by the criteria's for evaluation and recognition of the headings of the balance sheet.

While the Forth European Directive is imposing mandatory schemes for assigning the balance sheet, IAS1 centers on a series of minimal requests concerning the structure and the content of the balance, with a very strong accent on the content (the core), without prescribing the order or the format of the elements.

The IAS1 standard states in paragraph 66, that the balance sheet must have minimally the next headings: 


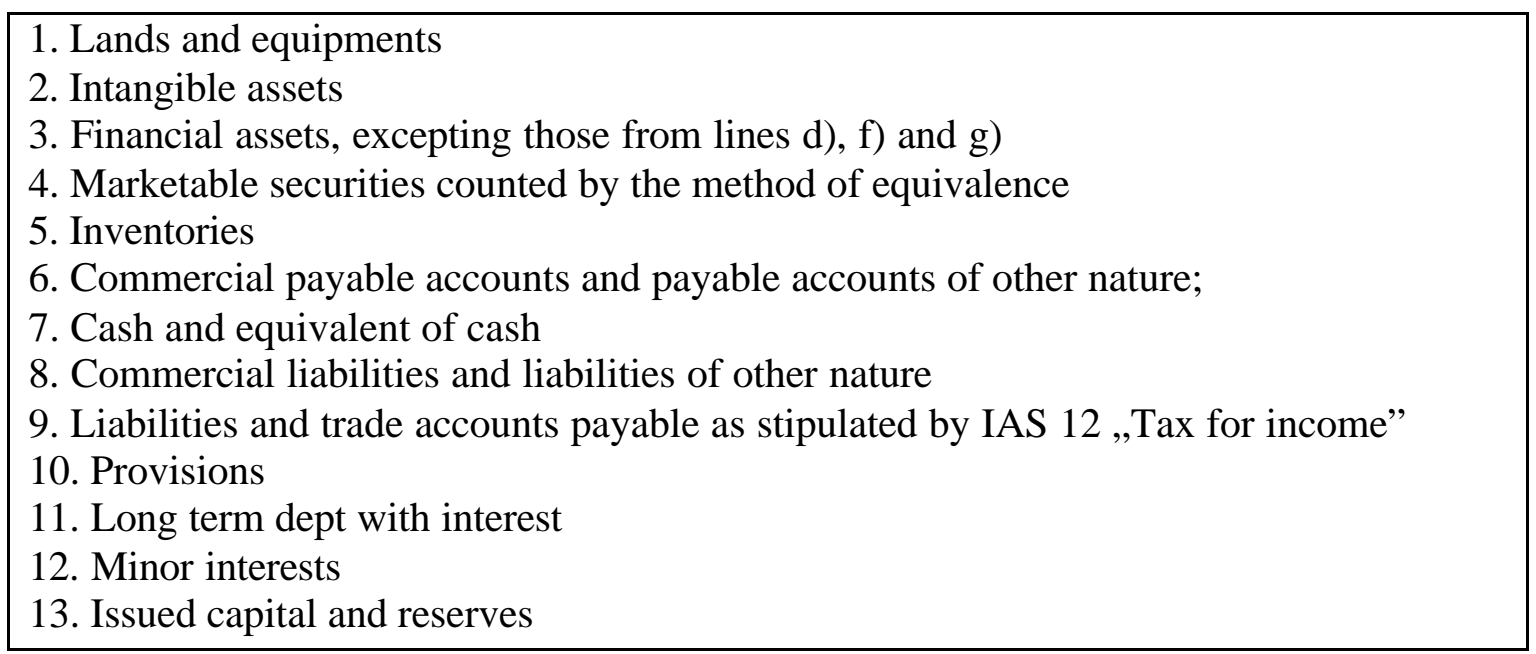

Exhibit 2: The balance sheet form according to IAS1

The stipulations of IAS1 are more relaxing than the ones from the Directive, meaning: they don't prescribe the format of presentation for the elements, but they require a separate presentation of the elements, so as to ensure an accurate image of the financial position of the company. The reasoning concerning the separate presentation of other elements in the balance sheet, are based on three criteria's represented in IAS1 la paragraph 70: the nature and liquidity of the assets, and also the fair value, conducting to a separate presentation of the commercial fund and the assets, resulted from development costs, of the financial and non-financial assets, and also the current assets and plant assets. The function of the currents assets in the company, is conducting to a separate presentation of the financial assets and the ones used in exploitation, the inventories, the payable accounts, of the cash and cash equivalent. The amount, the nature and delimitation in time of the dept, is conducting to a separate presentation of the long term depts, including the interest and the provisions classified in current and long term ones.

Even though, the new balance sheet format, approved by OMPF no. 1752 from 2005, is really close as a structure and conception by the stipulations of international accounting reference, there are some small incompatibilities with the standard IAS1: in the proposals of bilateral scheme from the append to IAS 1, ,intangible assets" appear after ,lands and equipments”, while as in the balance sheet format proposed by OMPF no. 1752 from 2005, these appear as the first heading; in the Romanian accounting environment, the result - loss or earning - of the value exchange is treated as an element of the financial result, while as IAS standards treat them as elements of the exploitation; according to IAS, the prepaid expenses and prepaid incomes should be included in the structure of current assets and liabilities, while as OMPF no. 1752 from 2005 stipulates that these remain as deferred revenues; in the proposals of bilateral scheme found in the appendix to IAS 1, the ,provisions for risk and other costs” are stipulated into liabilities as it follows: „retained tax and liabilities for retirement" are included in the structure of long term depts., and the ,provisions for guarantees" are included in the structure of current liabilities. While as the new balance sheet format approved by OMPF no. 1752 from 2005, the heading ,provisions for risk and other costs" are stipulated as a distinct element in the balance sheet, including provisions retained tax, for retirement and other similar obligations, and also other provisions (for disputed issue guarantees accorded to the customers); in the international accounting environment, ,allocation for investments" is stipulated as prepaid income, by either modifying the value of the asset which is allocated, while as in the new Romanian balance sheet format, the heading ,prepaid income" takes over the balance of the account 131 „Subventions for investments”. In order to respect the recommendations made by IASB, it would be indicated the exclusion of the allocations from the first class of accounts, so as to create a truce. 
The balance sheet seen from the perspective of the new development program of the Romanian accounting system

The balance sheet approved through OMPF no. 1752 from 2005 is a vertical scheme (list), inspired by the Anglo-Saxon model, according to the Forth European Directive completed and modified with the Seventh European Directive and harmonized with the international accounting standards. The balance sheet - format list - emphasis the owned assets, thing mirrored by the relation „Owned assets = Assets - Liabilities”. The number one priority is the efficiency of the stockholders assets - which is also the main characteristic of Anglo - Saxon model.

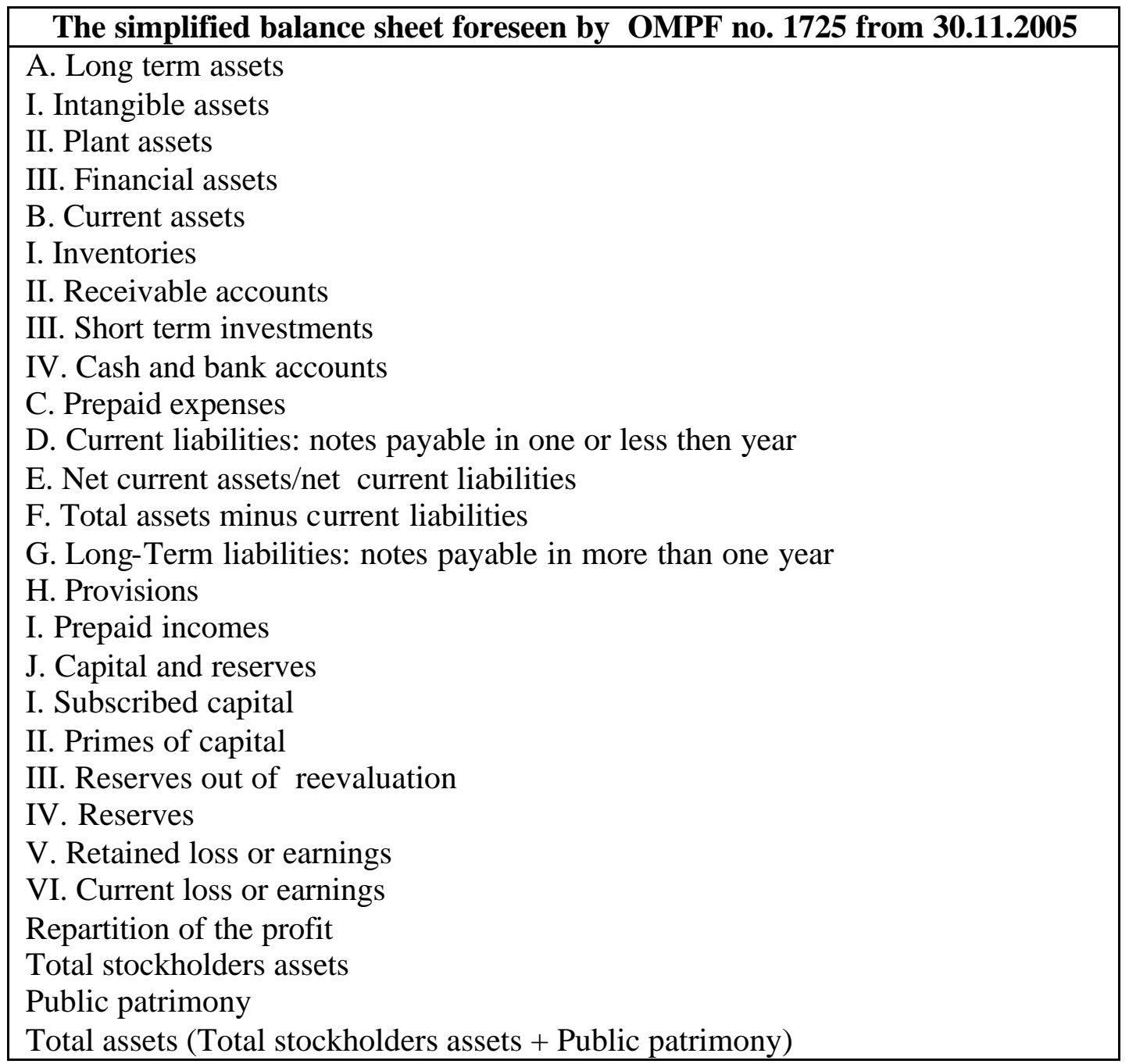

Exhibit 3: The balance sheet form according OMFP 1752/2005

The main classification criteria - for the elements of passive and active remain: the destination and the origin. In the new stipulation it is kept the structure of the active after the criteria of reversed liquidity. Structuring the elements of active in decreasing order (reversed) of liquidity is adopted by some European states, including Romania.

Before estimating ,total assets”, there are extracted the liabilities with notes less than a year (elements of passive), and afterwards we can determine the indicator ,net current assets/net current liabilities”. The value of ,total assets” does not exist, there is only the „,net assets”, after which are extracted the long term dept, the provisions for risk and costs the prepaid incomes and owners capitals. 
The ordering of the passive elements is made in the order of maturity decreasingly. This principle is also applied in USA and consists in ordering the elements of passive, starting with the resources that have the smallest maturity, and going on with the resources that have a longer eligibility. All these stipulations of grouping the headings in the balance sheet are subordinated to the Anglo-Saxon conceptions, favoring the external users in getting an accurate image concerning the financial situation of the company.

The total active of the balance sheet is determined by adding the elements from the lines A, $\mathrm{B}$ and $\mathrm{C}$, and the total of the passive of the balance sheet is determined by adding the elements from lines D, G, H, I and J.

The schemes for horizontal balance sheet are appreciated by those economies where main financing is made by banking, while as the vertical schemes balance sheets are appreciated by those economies where the main financing is made through the stock market.

The new balance sheet format is inspired by the Britain's system. The financial AngloSaxon situations are oriented to satisfy the informational needs of the investors. Introducing in our country the scheme list (vertical) represents a „major step”, because it opens up to the economic financial analysis, and offering some valuable information for a larger category of users.

We assist to the development of the headings with liabilities and payable accounts, and also to the presentation of these in two categories of maturity - liquidity.

Long term debts, to be reimbursed in more than one year, were structured in: „Current liabilities: notes payable in one or less then one year” (line D) and „Long-Term liabilities: notes payable in more than one year" (line G).

Some elements of the dept and assimilated liabilities for long and medium term appear in the structure of permanent capitals (line G) and also in the structure of current liabilities (line D). This is a flaw that will lead to several impediments concerning the activity of the annalists from the accounting and financial field.

Separating for good the long term payable account and the long term liabilities from the short term ones is still a delicate ,subject”.

In the Anglo - Saxon environment it is foreseen that the part of the medium term payable account and the medium, that become mature in less than one year will have to be registered in the structure of current liabilities and payable accounts, by the criteria of expiration.

There is also another conception that emphasis the nature of the payable account or liability.

The new balance sheet format is emphasizing a series of indicators, so the line F „Total assets minus current liabilities" reflects the net current situation of the patrimony, which is not influenced by the debts payable in a period of time larger than one year. (line E), and is highlighting the existence or the deficit of the working capital".

Presenting the liabilities into two categories represents a major step, because the permanent capitals can be easily determined, and they represent the sources of finance that the company can use. The banks are using this indicator, to determine the degree of covering the invested capitals through the ratio permanent capitals/invested capitals.

According to OMPF no. 1752 from 2005, section 7, alignment 71, the ,constitute costs” represent „Costs accrued by creating or developing a company”, and the period of absorption is maximum five years.

In the structure of ,intangible assets" are not included the costs with the research anymore. According to the international accounting standard IAS 38 „Intangible assets”, the costs with the research should be included in costs, only when they performed, because in the phase of research of a project, the company can't demonstrate that there will be an intangible asset which will generate future economical advantages.

According to OMPF no. 1752 from 2005, section 7, paragraph 78, it is stated, concerning the commercial working capital, that it is allowed a period of absorption is maximum five years. Although the companies can absorb the commercial working capital, systematically, in a period 
greater than five years, on the condition that this period should not be greater than the economical use of active.

In the case of permanent assets they were classified into plant assets and un-plant assets. The structure of financial fixed assets was modified through the highlight of separate accounts for the participants from the group and associated companies.

So we find ourselves, at the beginning of the road concerning the consolidation of the accounts, though the need to constitute company groups in our country is greater and greater, and the accounting solutions concerning the last ones are just a project for now. Through OMPF no. 1752 from 2005 it is opened the way to consolidation of the accounts so that they can be more efficient. The international accounting standards IAS27, IAS28 and IAS31 could be the ultimate inspiration for the Romanian standardizers. In the balance sheet there will be highlighted the whole investment effort of a company, indifferently of the stage of the project.

We can state that the new balance sheet format, respected the program for development of the Romanian accountancy system, and opens up to a better economic-financial analysis and to satisfying the informational need of the investors.

\section{References}

1. Bogdan, Victoria, 2005, Armonizarea contabila internationala, Bucuresti, Editura Economica.

2. Bunget, Ovidiu Constantin, 2005, Contabilitatea româneasca între reforma si convergenta, Bucuresti, Editura Economica.

3. Cotlet, Dumitru, Megan, Ovidiu, Pelin, Andrei, Pistol, Ion, 2005, Situatiile financiare anuale, Timisoara, Editura Orizonturi Universitare.

4. Dutescu, Adriana, 2003, Politici contabile de intreprindere, Editura CECCAR.

5. Feleaga, Niculae, Malciu, Liliana, 2004, Dincolo de frontierele vagabondajului contabil, Bucuresti, Editura Economica.

6. Feleaga, Niculae, Malciu, Liliana, 2004, Reforma dupa reforma: Contabilitatea din România în fata unei noi provocari, Bucuresti, Editura Economica.

7. Ionascu, Ion, 1997, Epistemologia contabilitatii, Bucuresti, Editura Economica.

8. Pop, Atanasiu, 2000, Contabilitatea financiara româneasca armonizata cu Directivele Contabile Europene si cu Standardele Internationale de Contabilitate, Deva, Editura Intelcredo.

9. Collase, Bernard, 2000, Cadres comptable conceptuels, Encyclopedie de la Comptabilité, du Control de Géstion et de l'Audit, Paris, Economica.

10. Walter ,T. Harrison jr., Charles, T. Horngren, Financial Accounting - Second Edition, New Jersey, Prentice Hall Englewood Cliffs. 